\title{
Economia e política na crise global
}

\author{
OtAVIO SOARES DULCI
}

A

CRISE COMEÇOU sorrateira, provocada pelo furo da bolha imobiliária nos Estados Unidos. Estávamos em meados de 2007, e o que parecia ser

um desarranjo setorial - hipotecas concedidas sem garantias suficientes - era visto pelo resto do mundo como um problema norte-americano. Porém, logo se constatou que em torno das hipotecas se erguera uma monumental engrenagem financeira, com títulos sobre títulos que funcionavam numa dinâmica especulativa desvinculada do valor real dos bens a que se referiam na origem. O tamanho do problema crescia a cada nova notícia sobre o envolvimento dos bancos e dos investidores de várias partes do mundo nesse jogo sem medidas.

No Brasil, enquanto isso, o ambiente econômico brilhava de forma inédita. O ano de 2007 foi de grandes projetos, governamentais e privados, anunciados numa atmosfera de otimismo que se estendeu para 2008, com maior vigor até. Não se ignorava, por certo, o andamento da crise financeira em outros países, mas sua influência sobre o Brasil e outros países ditos “emergentes" era considerada residual. Durante um bom tempo, predominou na discussão o tema do descolamento das economias emergentes em face da crise nos países centrais.

Dada a crescente integração de tais economias ao capitalismo global, não seria razoável imaginar que elas ficassem imunes às turbulências. O que se buscava avaliar era o grau de seu descolamento, supondo-se que o impacto da crise ocorre diferentemente segundo as características e as circunstâncias de cada país. Esse é um aspecto de grande importância na análise do processo, até mesmo para orientar as políticas governamentais e as decisões dos agentes privados. Assim, no caso do Brasil, que nos interessa mais de perto, faz sentido aferir suas condições específicas, os fatores de vulnerabilidade e as vantagens comparativas com que o país pode contar em cenário tão instável.

Observa-se que o Brasil ficou relativamente protegido do desastre do sistema financeiro nos Estados Unidos e na Europa, graças à solidez de seus bancos e à melhor supervisão dos órgãos públicos encarregados desse setor. Esses, a começar do Banco Central, se revelaram mais estruturados e focados do que seus congêneres em diversos países importantes. Além disso, as regras brasileiras não facilitam o jogo de papéis que levou tantos bancos tradicionais em outros países ao delírio e em seguida à insolvência. Assim, pelo lado das instituições, temos vantagens que foram construídas ao longo do tempo - os muitos anos de apren- 
dizado no combate à inflação, em busca da estabilidade da moeda, resultando nas cautelas que hoje nos ajudam a atravessar a tempestade.

Pelo lado da produção e do comércio, porém, a crise atingiu gradualmente os países emergentes em duas vertentes: uma, a do crédito, que ficou difícil, caro e eventualmente paralisado, no mercado interbancário e no fluxo dos bancos para as empresas; outra, a da queda de preços dos produtos básicos de exportação, ou commodities, matérias-primas e alimentos que, por sinal, haviam atingido elevadas cotações no começo de 2008.

Com efeito, o preço do petróleo chegou às alturas, o álcool combustível ganhou destaque como alternativa, e daí se desencadeou um debate global a respeito da inconveniência do cultivo da cana em larga escala, pelo seu impacto ambiental e, especialmente, pela pressão que os canaviais causariam sobre a oferta de alimentos. Usar a terra para alimentar motores em vez de alimentar gente é uma ideia chocante, sem dúvida, mas, se a discussão envolvia bons argumentos, estava também influenciada por múltiplos interesses, entre os quais os das indústrias de combustíveis fósseis, competidoras dos biocombustíveis. De todo modo, os acontecimentos evoluíram com tal rapidez que a polêmica sobre a falta de alimentos parece hoje tão remota que provavelmente será esquecida na narrativa da crise - até que o problema reapareça, pois o risco não pode ser negligenciado.

O ano de 2008, assim, foi de um extremo ao outro. Começou sob ameaça de inflação e carestia. Terminou com recessão, desemprego e ameaça de deflação.

E agora? O que vai acontecer? Essa é a pergunta cuja resposta vale ouro. Todos estão à procura de orientação e as opiniões são bastante desencontradas. Há previsões soturnas, assim como vaticínios mais animadores. Os indicadores da atividade econômica são examinados com lupa. $\mathrm{E}$ as informações recorrentes sobre os passivos dos bancos e instituições financeiras são avidamente acompanhadas para se saber o tamanho dos rombos a serem equacionados.

Esse é o cenário em que se movem os especialistas - os economistas, os analistas do mercado, os empresários, os rentistas e investidores. Eles dispõem do instrumental técnico para interpretar os fatos econômico-financeiros e avaliar seus desdobramentos. Neste texto, não pretendo avançar nesse terreno, mas contribuir para uma agenda de análise que incorpore aspectos políticos, sociais e históricos à apreciação da presente crise, em conexão, naturalmente, com os aspectos econômicos que ocupam o centro das atenções.

\section{Elementos para uma agenda de pesquisa}

Comecemos por indicar alguns elementos de cunho teórico e metodológico que merecem exame detido. O primeiro diz respeito ao fato notável de que a crise veio como uma grande surpresa não só para o público em geral, mas também para os especialistas. Poucos a previram. E quem a antecipou foi visto como desmancha-prazeres ou mesmo como voz interessada no jogo especulativo. 
Alan Greenspan, que presidiu o Banco Central norte-americano (Federal Reserve) até o início de 2006, já havia advertido, dez anos antes, para a "exuberância irracional" do mercado de ações. Estava em posição privilegiada para observar o que se passava. Até mesmo no tocante às hipotecas subprime e aos títulos garantidos por elas. É bastante revelador que Greenspan não tenha interferido como autoridade reguladora em algo tão duvidoso. E não o fez por confiar na capacidade de autorregulação do mercado. "Eu cometi um erro em supor que o interesse das organizações, especialmente dos bancos e de outras empresas, faria que elas estivessem mais bem capacitadas para proteger seus próprios acionistas e suas ações nas empresas", disse Greenspan em depoimento a uma comissão do Congresso norte-americano, no dia 23 de outubro de 2008. $\mathrm{E}$ acrescentou: "Aqueles de nós que acreditavam que era do interesse das instituições credoras proteger seus acionistas, incluindo eu, estamos incrédulos, em estado de choque". ${ }^{1}$

O que está em causa, nessa declaração, é o próprio fundamento filosófico do sistema de livre-mercado: a ideia da mão invisível, guiada pelo autointeresse dos agentes e por sua capacidade de escolha racional das decisões, resultando, no agregado, em benefícios coletivos. A economia, como ciência, construiu em três séculos todo um acervo de proposições teóricas, fórmulas de medição, técnicas de teste e resultados empíricos robustos. Boa parte desse acervo se inspira no fundamento da mão invisível. Ora, as limitações do paradigma ficaram patentes na crise. O desastre não foi vislumbrado, ou, se deu pistas, essas não foram adequadamente lidas. Estão à mostra certas insuficiências críticas na teoria econômica e em sua aplicação ao mundo real.

Os demais cientistas sociais, no entanto, não podem contar muita vantagem sobre os economistas. Pois nenhum cientista político previu, por exemplo, a queda do muro de Berlim e as profundas transformações que esse evento ocasionou. Sinais de mudança se manifestaram no Leste Europeu ao longo de toda a década de 1980 - e a abertura de Gorbachev marcou boa parte desse período -, mas o muro caiu em 1989 como uma grande surpresa para todos.

É bom recordar aquele momento da história contemporânea, na medida em que ele guarda relação com o processo subsequente de expansão do capitalismo desregulamentado, como bem apontou Rubens Ricupero (2008) em análise recente. E também por outro motivo: para ajudar a pensar na dificuldade da ciência em dar conta do comportamento humano em sociedade. O estudo do campo econômico é cheio de incertezas, tanto quanto o estudo do campo político. E ambos ganham em alcance explicativo quando cooperam entre si.

Uma forma de enfrentar tais incertezas é trabalhar simultaneamente com o longo prazo e o curto prazo. Ou seja, com um olho no processo histórico e outro olho na conjuntura. Esse é o segundo elemento a ser destacado na agenda de pesquisa da crise.

Assim, focalizar o nexo entre a queda do bloco soviético e a trajetória 
subsequente do capitalismo que resultou nos problemas de hoje é um tipo de abordagem histórica de longo prazo. Mas a indagação sobre como os eventos aconteceram, e em que sequência, é respondida por análises de conjuntura.

Reconstituir as conjunturas é maneira esclarecedora de explicar crises. A quebra de 1929 e a Grande Depressão da década de 1930 propiciaram obras relevantes nessa linha (Galbraith, 1977). Sua leitura nos oferece o encadeamento de fatos e de personalidades que acabaram por convergir para o desastre financeiro. Contudo, tal desfecho não estava dado: foi construído por uma série de decisões ou indecisões de atores bem definidos. Uma qualidade cognitiva da análise de conjuntura é evitar visões fatalistas, rigidamente deterministas, permitindo observar a história como obra aberta, feita pelos próprios homens - embora não do jeito que querem, como ressalvou Marx.

O exercício da história contrafactual é interessante para rascunhar cenários alternativos ao que de fato ocorreu. Suponhamos que certas decisões individuais tivessem sido diferentes. Por exemplo, que Greenspan tivesse interferido na bolha das ações, quando emitiu sua opinião sobre a "exuberância irracional", em meados da década de 1990. Ou, então, que as autoridades norte-americanas, em setembro de 2008, não tivessem deixado o banco Lehman Brothers afundar. Esse evento é considerado, unanimemente, como o marco crucial do processo, ou seja, o ponto de inflexão que o transformou numa crise de confiança generalizada. E resultou, claro, de uma tomada de decisão política, calcada em visão análoga à de Greenspan. Havia uma razão de princípio a fundamentá-la: não é correto cobrir com o dinheiro público o rombo de um banco privado. Se os lucros são dos gestores e acionistas, por que as perdas deveriam ser repassadas ao povo? E havia também uma razão prática: salvar um banco agonizante abriria um precedente para salvar outros - e até onde iria o buraco? No entanto, foi uma decisão malcalculada, a julgar por seus efeitos devastadores em todo o mundo e pela súbita mudança de atitude dos próprios decisores, que logo passaram a preparar medidas de resgate de outros bancos fragilizados.

Nesse mesmo terreno em que se cruzam os fatos econômicos e políticos, cabe mencionar outro fatídico setembro: o de 2001. Os ataques terroristas a Nova York e Washington deram lugar a um quadro sombrio dentro dos Estados Unidos, levando o Banco Central norte-americano a relaxar controles como forma de reanimar a economia. Muitos analistas localizam nessa conjuntura a origem da bolha das hipotecas.

Um terceiro elemento da agenda diz respeito à importância de identificar diferenças no impacto da crise em países e regiões do mundo, algo que foi mencionado de passagem no início deste texto a propósito do caso brasileiro. Nos últimos tempos, testemunhamos crises econômicas internacionais de vários calibres - a crise do México, a da Rússia, a do Sudeste Asiático - que contagiaram outros países ditos emergentes, como o Brasil, por canais de transmissão de desconfiança. Nesses casos, o Fundo Monetário Internacional (FMI) e seu par- 
ceiro, o governo dos Estados Unidos, atuaram para coordenar resgates em troca de contrapartidas amargas. A crise de agora é bem distinta na medida em que emergiu no coração do capitalismo global: Wall Street. Daí se disseminou por toda parte, mas seu impacto parece variar conforme o envolvimento de países, instituições financeiras e empresas com esse epicentro e suas práticas.

O circuito é planetário, mas não é homogêneo. Na virada de 2008 para 2009 , verificou-se que os países centrais estavam entrando em recessão. Sobre os países emergentes, porém, o efeito tem sido um pouco diferente. Suas economias apenas desaceleraram, reduzindo a marcha em comparação com os altos índices de crescimento experimentados nos últimos anos. E entre eles há distinções a fazer. Variáveis como o tamanho do mercado interno de cada país e o seu grau de autonomia em relação à economia mundial são cruciais como dimensões de vulnerabilidade ao contágio da crise. Além disso, as condições do sistema financeiro interno, e sua dependência do exterior, certamente contam, e muito.

O caso da Islândia ilustra de modo exemplar a incidência de desvantagens em todos esses itens. A Islândia, simpático país de 300 mil habitantes, vivia da indústria pesqueira e do turismo, até que, no início do século, deu um passo ousado, tornando-se centro financeiro de grande porte. Seus poucos bancos atraíram aplicações de inúmeras origens. Foi celebrada como uma espécie de vitrina dos benefícios do livre-fluxo de capitais. Porém, quando os ventos mudaram, o sonho se desmanchou grotescamente.

Outros países, na Europa Central e Oriental, também se têm mostrado bastante vulneráveis aos altos e baixos no fluxo de recursos externos, e sem meios de reagir por iniciativa própria. Aí, sim, a queda do crescimento pode ser mais profunda e duradoura, tanto que o Fundo Monetário, que andava inoperante, reapareceu para jogar a boia e resgatar esses náufragos. Desde fins de 2008, o FMI concedeu empréstimos para a Ucrânia, a Bielo-Rússia, a Letônia, a Hungria e a Sérvia; outros países da região provavelmente terão que fazer o mesmo.

\section{A globalização neoliberal: origens e desdobramentos}

A atenção às diferenças é a base para elaborar comparações a partir das quais se possam extrair inferências mais sólidas sobre a crise e seus desdobramentos do que permite o volume de conhecimento que temos hoje. Por enquanto, sabemos ainda pouco. Palpites de todo tipo têm circulado pelo mundo, e nem sempre transmitem suficiente consistência analítica. Diante disso, podemos tomar como bússola as transformações das últimas décadas e, nesse contexto, situar o que está acontecendo agora. Um balanço do passado é imprescindível para qualquer antecipação do futuro.

O cerne das mudanças que se observaram nos últimos trinta anos é bem descrito pela ideia de globalização neoliberal. Houve um processo de integração dos povos do mundo propiciado por vertiginosas inovações tecnológicas e organizacionais, que incidem na esfera da cultura e nas formas de sociabilidade. 
Embora esse movimento seja comumente associado às relações econômicas, seu alcance tem sido muito mais vasto.

René Dreifuss (1996, p.157), em estudo detalhado do tema, propôs a utilização de conceitos distintos para cobrir toda a complexidade do processo. Designou por "globalização" a sua face econômica, relativa aos fenômenos da esfera da tecnologia, da produção, das finanças e do comércio, "que atingem de forma desigual e combinada todos os países da Terra, e não somente aqueles que operam em escala mundial" (ibidem). Para as mudanças nos âmbitos societário, cultural e político, sugeriram dois outros termos: "mundialização", representando a tendência à homogeneidade de comportamentos, padrões de consumo e estilos de vida; e "planetarização", referente ao âmbito político-estratégico, aos deslocamentos de poder em escala transnacional. $\mathrm{O}$ aparente jogo de palavras traduz bem a variedade de aspectos a serem examinados no tratamento do assunto.

O renascimento do liberalismo, após longo período de desprestígio, deu a justificativa intelectual às políticas que fomentaram o conjunto de transformações globais. Tais políticas, resumidas no lema "menos Estado, mais mercado", se pautavam pela primazia da liberdade individual sobre a equidade social, buscando distanciar a economia e a política.

Representaram, nesse sentido, uma inversão do arranjo institucional predominante no mundo a partir da Grande Depressão - economia politicamente regulada e políticas de bem-estar social. Por esse antigo arranjo, os Estados haviam assumido controle mais direto da vida econômica, de início para debelar os efeitos da crise. Exemplo clássico dessa guinada foi o New Deal do governo Roosevelt, nos Estados Unidos. Mais adiante, os Estados passaram a desempenhar novos papéis, de planejamento, de financiamento de projetos privados e mesmo de investimento direto (em empresas de capital misto ou plenamente estatais). Paralelamente, adotaram-se políticas de cunho social que também contradiziam o antigo consenso liberal-individualista. Leis de proteção aos trabalhadores foram introduzidas, assim como sistemas previdenciários e serviços sociais de massa, configurando o que se chamou Estado Providência ou Welfare State.

Houve variações relevantes entre os países no tocante à margem de intervenção estatal na economia e na provisão de bem-estar social. Convém que tais variações sejam mencionadas aqui, pois têm muito a ver com o que aconteceu depois e também com as perspectivas de futuro.

$\mathrm{Na}$ área econômica, a variação principal se liga ao fenômeno do desenvolvimento desigual, que ensejou uma importante gama de teorias a respeito do atraso econômico e suas consequências. A noção de que o atraso explica em boa medida as diferenças entre modelos de desenvolvimento iluminou fortemente os estudos dos processos de mudança macro-histórica, no terreno comum em que se encontram a história econômica, a política comparada, a sociologia histórica e a economia do desenvolvimento. Aventada por Trotsky e Veblen no início 
do século XX, essa hipótese foi testada por Alexander Gerschenkron (1965), o qual, estudando experiências de industrialização em diversos países europeus, concluiu que quanto maior é o hiato econômico a ser superado, maior o grau de politização (ou de "direção organizada", em suas palavras) de que se reveste o processo de sua superação. Ou seja, mais distante do sistema de livre-mercado, o qual corresponde ao modelo originário de industrialização (o modelo britânico), mas não é replicável pelos retardatários precisamente porque estão atrás e têm que buscar atalhos (ibidem). ${ }^{2}$

Ao lado dessa abordagem, que enfatiza fatores institucionais (particularmente o papel do Estado), tem-se uma vertente de estudos sociológicos que amplia o foco para abranger as tensões e os arranjos entre atores sociais relevantes ao longo da trajetória de modernização. As estratégias de elites e os interesses de classes são destacados como variáveis de peso para dar conta das diferenças entre os caminhos percorridos pelos países em direção à modernidade. ${ }^{3}$

No que diz respeito especificamente às políticas sociais, Esping-Andersen (1990), um dos principais especialistas do tema, estudou a formação de três tipos de Estados de bem-estar. Segundo ele, esses tipos se associam a determinadas configurações sociais e políticas em cada país, notadamente coalizões de classes no poder. $\mathrm{O}$ resultado foi a montagem de diferentes esquemas de garantia de bem-estar.

Assim, há Estados com forte tradição liberal que limitam o direito à assistência publica aos comprovadamente necessitados, tratando de preservar o mais possível o mercado como eixo da vida social. O exemplo mais conhecido é o dos Estados Unidos. Em contraste, há aqueles Estados de orientação socialista, como a Suécia, onde o sistema de bem-estar é universal, montado para todos, com financiamento estatal. E há um terceiro tipo, chamado corporativo, que se originou na Europa Continental. Benefícios sociais foram aí adotados pelos Estados para contemplar categorias selecionadas (por exemplo, os militares e funcionários civis) e se estendeu com o tempo para outros setores. Conhecemos bem essa terceira fórmula, que foi aquela pela qual o Brasil começou a erguer o seu sistema de previdência e assistência social na primeira metade do século XX. E que ainda tem reconhecida influência na vida do país, a despeito de esforços para manter serviços de caráter universal, como o Sistema Único de Saúde (SUS).

Não obstante as diferenças entre tais modalidades, a expansão de políticas sociais foi um traço marcante da fase posterior à Segunda Guerra Mundial em todo o mundo. Os anos de 1950 e 1960 se caracterizaram pelo predomínio crescente da ideia de promoção do bem-estar social como tarefa estratégica dos governos. Contudo, na década de 1970 o relativo consenso em torno dessa orientação começou a refluir, de tal modo que em pouco tempo se tornou corrente a percepção da "crise do Estado".

Para esse refluxo há várias explicações. Um esquema interessante é o ela- 
borado por Giuseppe Vacca (1991, cap.3), que distingue três dimensões do processo: a crise fiscal, a crise de legitimidade e a crise de governabilidade.

Em primeiro lugar, difundiu-se aos poucos o prognóstico de que a expansão do Estado do bem-estar apontava para um grave gargalo fiscal. Como financiar a demanda por serviços e gastos públicos, que crescia no ritmo do aprofundamento da democracia, da elevação dos níveis educacionais e da melhoria geral da qualidade de vida? Essa demanda não tem limites, ao passo que seu atendimento depende da capacidade de arrecadação do estado. A capacidade de tributar, por sua vez, é limitada por vários fatores, tanto econômicos quanto políticos. O nível de crescimento da economia é um deles: se a economia está crescendo, as coisas andam bem; mas, se há declínio, a arrecadação tende a cair, enquanto os gastos sociais tendem a aumentar (em razão do maior volume de auxílio-desemprego, dos piores índices de saúde que resultam do empobrecimento da população, e assim por diante).

As décadas de 1950 e 1960 foram prósperas. São lembradas como "anos dourados". Mas na década de 1970 a ordem econômica internacional do pósguerra deu lugar à crescente desordem, com crises sucessivas - os dois choques do petróleo, a crise da dívida externa dos países periféricos, rivalidades econômico-financeiras entre os países centrais. Pressões cruzadas se concentraram sobre os governos, vindas tanto do lado do capital quanto do lado do trabalho, reduzindo a margem de governabilidade do sistema.

Tais pressões se traduziam em análises opostas a respeito do Estado do bem-estar social e do que fazer com ele. A crise de legitimidade do Estado contemporâneo está ligada exatamente a essa divergência. Enquanto os donos do capital e seus órgãos de representação propunham enxugar o gasto social, os sindicatos e partidos trabalhistas questionavam o sistema de proteção como mecanismo de acomodação dos trabalhadores ao sistema capitalista. Esta última crítica, de inspiração socialista, apontava para as insuficiências do sistema de bem-estar. Teve seu momento, mas na década de 1980 perdeu fôlego diante do reaparecimento da perspectiva liberal, que caminhava em direção oposta: denunciava os excessos da ação estatal.

A crise, dessa perspectiva, resultaria do abandono dos princípios "naturais" da economia de mercado em favor de soluções políticas, portanto artificiais. Soluções como o dirigismo estatal sobre a vida econômica, o paternalismo do Estado do bem-estar, as leis trabalhistas e as pressões sindicais que deturpam o mercado de trabalho. Segundo o cânone liberal, a economia e a política são esferas separadas, que não devem se confundir. A expansão de direitos sociais e trabalhistas constitui interferência indevida da esfera política sobre a econômica, desnaturando a dinâmica do mercado. $\mathrm{O}$ resultado dessa confusão seria a crise do Estado junto com o declínio do crescimento da economia.

Tais ideias voltaram à tona quando o relativo consenso em torno do Estado do bem-estar deu mostras de esgotamento. E se apresentaram, ao longo 
da década de 1980, como modelo a ser adotado em lugar do que se esgotava. O rótulo que recebeu - neoliberalismo - traduz bem seu objetivo de restaurar velhas ideias para lidar com novas realidades.

O neoliberalismo, com efeito, era uma proposta de reencontro com a tradição liberal, mas não defendia - e nem seria possível - uma volta ao passado. O que o diferenciava de sua fonte clássica era, antes de tudo, o fato de que tinha que levar em conta a vigência de direitos sociais que fazem parte da noção moderna de cidadania, assim como a vigência de direitos políticos de sentido democrático difíceis de conciliar com a ética individualista (especialmente os que se referem aos sujeitos coletivos, como sindicatos, movimentos e associações diversas). Em outras palavras, entre as épocas do velho e do novo liberalismo se erguera toda uma arquitetura institucional que não podia ser simplesmente derrubada. Não haveria condições políticas para suprimi-la e provavelmente isso não seria de interesse do próprio capitalismo como sistema. Nenhum sistema de poder perdura sem um mínimo de legitimidade popular.

Diante disso, a fórmula neoliberal encontrou tradução adequada no lema "menos Estado, mais mercado". Tratava-se de transferir para a órbita do mercado tudo o que fosse possível, deixando ao Estado apenas o que não pudesse ser privatizado. $\mathrm{O}$ conceito é cristalino, mas sua aplicação prática não seria tão unívoca. Programas de inspiração neoliberal foram introduzidos por governos de inúmeros países, porém com muitas diferenças entre eles. Uma classificação genérica desses programas nos levaria a distinguir, pelo menos, entre os governos de orientação conservadora e os governos de filiação social-democrática (e até socialista, como no caso da China). Os primeiros tendiam para um liberalismo afirmativo, visceralmente ideológico, enquanto os segundos promoveram uma mistura pragmática de ideias liberais e sociais.

O neoliberalismo conservador teve como ícones o governo Thatcher, no Reino Unido (1979-1991), e a gestão Reagan, nos Estados Unidos (1981-1989). Desta última foi cunhado o termo Reaganomics para designar a orientação econômica então introduzida, que tinha como carro-chefe o incremento da oferta (supply side). Já a assimilação de políticas neoliberais por governos social-democráticos teve como exemplo mais conhecido a Espanha sob Gonzalez (19821996), que serviu de modelo para diversos governantes latino-americanos, assim como a França durante a era Mitterrand (1981-1995). Todos adotaram medidas de "menos Estado, mais mercado", mas cada um em seu ritmo e com propósitos diferentes.

Num olhar retrospectivo, pode-se sugerir uma periodização desse processo de globalização neoliberal em três fases. A primeira, de 1979 a 1989, começou com a ascensão de Thatcher ao poder no Reino Unido e culminou com a queda do muro de Berlim. Foi a fase da afirmação do projeto tanto no plano econômico quanto no plano político. Traduziu-se, no cenário britânico, pela estratégia de privatizações e pelo confronto com o movimento sindical, para 
subjugá-lo e impor a hegemonia do capital nos novos moldes. Já no cenário norte-americano, a desestatização não envolveu privatizações (pois o país não tinha companhias estatais para vender), e sim desregulamentação em larga escala, ao lado do acirramento do confronto com o bloco comunista, numa impressionante escalada armamentista e tecnológica que o enfraqueceria de modo decisivo. Aos pensadores e ideólogos liberais, atuantes na formulação econômica, somaram-se os neoconservadores, defensores da missão dos Estados Unidos de implantar mundialmente a democracia liberal, pela força se necessário. Era uma corrente intelectual em ascensão que defendia o fortalecimento militar do país para projetar globalmente seus interesses e princípios com clareza moral e sem rebuços.

Na década de 1990, a globalização neoliberal atingiu o seu auge. Com o fim da guerra fria, estabeleceu-se a pax americana no planeta, uma espécie de comando benigno do sistema internacional pela única superpotência em ação. E os ideais da liberalização se disseminaram na mesma medida, codificados no célebre Consenso de Washington. Reformas pró-mercado, livre-comércio, livrefluxo de capitais, afrouxamento de normas de regulação - tudo isso acarretou, pelo mundo afora, crescimento econômico, melhoria da renda familiar e redução dos níveis de pobreza (mas não da desigualdade social, que de fato tendeu a aumentar). No entanto, pipocaram crises sucessivas em países periféricos, que, exatamente por serem periféricos, não serviram de alerta para identificar problemas sistêmicos. Tais crises foram, em geral, encaradas como deficiências localizadas, a serem curadas por mais doses do mesmo remédio (ou seja, "menos Estado, mais mercado"). ${ }^{4} \mathrm{~A}$ autoconfiança dos dirigentes e ideólogos do modelo chegou às alturas. Um exemplo: nos Estados Unidos, o governo Clinton aprofundou a política de desregulamentação de Reagan, ao abolir em 1999 a separação entre bancos comerciais e bancos de investimento, norma prudencial que vinha dos tempos da Depressão. Tal medida, hoje se percebe, incentivou a barafunda financeira que desencadeou a crise de 2008.

A terceira fase se abriu em 11 de setembro de 2001, com os ataques terroristas a Nova York e Washington. Esse evento dissolveu o otimismo da pax americana, substituído pela mobilização contra o terrorismo. Nos Estados Unidos, as posições beligerantes dos neoconservadores ganharam relevo, com a aplicação de teses como a da guerra preventiva e do intervencionismo unilateral do país, atropelando a já frágil capacidade de coordenação das Nações Unidas. Cresceu também a influência da direita religiosa, aliando seu conservadorismo moral ao patriotismo messiânico em voga. O governo Bush serviu de estuário para essas diversas correntes. A orientação econômica foi mantida, expandindose o consumo pelo crédito abundante. Contudo, a política liberal da década de 1990 não teve mais lugar. Nesse ambiente, sobreveio a crise financeira.

\section{O que está mudando?}

Esse breve panorama sugere uma visão pendular da equação mercado/ 
Estado. O século XX foi o século do Estado, na medida em que se destacou por projetos políticos apoiados em Estados ativos e intervencionistas: o comunismo de tipo soviético, o fascismo, a social-democracia e o capitalismo regulado, keynesiano. É evidente o contraste com o século XIX, este assinalado por um crescente consenso em torno dos ideais do liberalismo. Já se manifestavam, nessa época, os traços principais de uma economia globalizada, unida pelo comércio, por redes de transportes e comunicações, por fluxos de capitais e de mão-deobra migrante.

O século XX, contudo, começou e terminou sob a égide do livre-mercado. A primazia do Estado e a sustentação de projetos de regulação econômica e social corresponderam, a rigor, ao período entre 1914 e 1989. Mais precisamente, o "breve século XX", como o chamou Hobsbawm, teve como eixo a ascensão, a expansão e a decadência do comunismo soviético. Em grande parte, foi em contraponto a essa fórmula de revolução social que se estabeleceram os outros três projetos estatistas antes referidos. Para não falar do refluxo das ideias liberais, que envelheceram e perderam influência por décadas.

Estas últimas voltaram recicladas, apresentando-se como alternativa à crise do Estado. A balança pendeu para o mercado. O princípio da despolitização da economia ressurgiu, concretizando-se nas iniciativas de privatização, desregulamentação e redução das tarefas dos Estados (bem como de seu tamanho e custeio). Mas o manejo de recursos políticos, de meios de poder, foi essencial para que tudo isso ocorresse. Apenas por credulidade ideológica se poderia dizer que o mercado estava a recuperar sua função de arcabouço espontâneo da vida social. Da periodização que sugerimos antes, podemos inferir que o projeto de globalização neoliberal se afirmou dialeticamente, por confrontos contra antagonistas internos (sindicatos, funcionalismo público, movimentos sociais) ou externos (o bloco comunista, depois as redes de terrorismo e o "eixo do mal"). Alimentou-se dessa mobilização contra inimigos reais ou fabricados.

A hegemonia do capitalismo financeiro, ao ponto a que chegou, só poderia ser alcançada pela via política, mediante o manejo oportuno de recursos de poder. Pode-se buscar uma demonstração disso pelo estudo das relações entre elites econômicas e políticas nos diversos países do mundo. Alguém utilizou a imagem da "porta giratória" para retratar a circulação constante de membros das elites entre cargos no governo e nas companhias privadas. $\mathrm{Na}$ área financeira esse vaivém é notório e afeta a governabilidade do sistema, como ficou claro na presente crise. Talvez essa realidade seja o que caberia esperar de um deslocamento do tipo "menos Estado, mais mercado", significando menos poder para a burocracia e mais poder para os empresários, os banqueiros e os gestores privados em geral. Faz sentido, desde que as responsabilidades sejam adequadamente exercidas. Hegemonia, para lembrar Gramsci, é liderança intelectual e moral.

Por isso, o absolutismo do capital financeiro foi posto em xeque, sendo esse um dos principais resultados da crise. $\mathrm{O}$ capitalismo como sistema não corre 
riscos, mas os bancos, as instituições de investimento, as agências de análise de risco e toda a parafernália que se desenvolveu ao seu redor, esses sim, perderam muitos pontos. Para reconstruir sua reputação, os bancos e os agentes do mercado financeiro terão que reencontrar sua função primordial de apoio à economia real.

Essa é uma afirmação normativa, mas tem seu lado prático, uma vez que os grandes bancos internacionais não estão conseguindo enfrentar a crise sem recorrer à ajuda dos governos. Portanto, têm que se submeter a certas condições políticas. Os governos, representando a opinião pública, pedem mais transparência e austeridade de gestão, diante das revelações dos enormes salários, mordomias e gratificações com que se locupletavam os administradores dos bancos e instituições à beira da insolvência. De fato, uma autêntica bolha salarial, desligada da realidade. E pior: desligada dos interesses das próprias firmas, que estavam pagando caríssimo a quem, por ganhos de curto prazo, as conduzia ao buraco. Nada mais distante da ética puritana de justificação do capitalismo.

Com o socorro dos governos aos bancos e às indústrias em apuros, rompeu-se o princípio da separação entre a economia e a política na dinâmica do mercado. Em outras palavras, os governos voltaram a participar diretamente do jogo, e em posição de força. Ainda que isso seja encarado como providência emergencial, é uma situação que movimenta o pêndulo na direção do Estado, com consequências que podem ir além da expectativa do mercado. Foi isso, precisamente, o que aconteceu na crise que se iniciou em 1929. Será que estamos diante do fim de uma etapa, como naquela época?

A comparação entre as duas crises tem sido frequente, e não por acaso. Os móveis dos agentes por trás dos dois eventos eram muito semelhantes. A direção do processo também seguiu o mesmo percurso, do centro para a periferia do sistema capitalista mundial. Ambas começaram na área financeira e se estenderam para a economia real. Ou, no contraponto sugestivo do debate norte-americano, começaram na Wall Street e daí se estenderam para a Main Street, onde vivem e trabalham os cidadãos comuns. No entanto, o mundo era bem diferente. Mais rural e provinciano do que hoje. Muitos dos atuais países eram colônias. O comércio era mais limitado, pois a escala das transações era relativamente modesta. A divisão internacional do trabalho diferenciava os poucos países industriais dos demais, que vendiam produtos agrícolas ou minerais e compravam bens manufaturados.

Seja como for, vale a pena considerar os desdobramentos políticos e sociais do crash de 1929. E eles foram de grande amplitude. Houve um colapso da crença no liberalismo e no mundo regido pelo mercado autorregulado. Em seu lugar, como já indicamos anteriormente, afirmou-se o Estado ativo, intervencionista, variando entre a intervenção moderada e a intervenção profunda, no limite chegando a ser total (totalitarismo). As ideias centrais da década de 1930 foram o Estado forte, o nacionalismo, o racismo, o corporativismo, a economia 
de comando e a politização da vida social. Em decorrência da crise econômica, os países se fecharam. Cada um tentou se arranjar por si. O comércio e as trocas declinaram. A ordem internacional ficou comprometida, o armamentismo se expandiu e uma solução para o desarranjo global só foi alcançada ao fim de uma guerra mundial que custou milhões de vidas. O único saldo positivo foi a valorização da questão social. Porém, em muitos casos (no Brasil, por exemplo), esse avanço vinha a substituir uma abordagem construtiva da questão democrática.

As consequências políticas mais nefastas daquela época (ditaduras e guerras) não parecem prováveis, pelo menos em curto prazo. Todavia, perseguições raciais não podem ser descartadas. Elas já têm se manifestado em conflitos étnicos na Europa e outras partes, e podem se agravar em razão do desemprego gerado pela crise econômica. Barreiras à imigração serão, quase certamente, apertadas, e, de qualquer modo, o êxodo dos pobres em direção aos países ricos não é promissor nessa época de vacas magras. Se o fluxo se inverter, com a volta dos emigrantes para casa, como farão os seus países para reintegrá-los, e ainda perdendo as remessas que antes eles enviavam do exterior? Nos países da América Central, por exemplo, esses recursos representam parcela relevante da renda nacional.

No aspecto econômico, há certas analogias que não chegam a surpreender. Um impulso semelhante ao da Depressão é o protecionismo. Veja-se, por exemplo, nas medidas iniciais dos Estados Unidos para enfrentar a crise econômica uma tendência a tratá-la como se fosse um problema interno do país, que não envolve o resto do mundo. Esse autismo se evidenciou nas tentativas congressuais de introduzir cláusulas de proteção ao produto nacional (buy American) no vultoso pacote de gastos públicos que o governo Obama preparou. É claro que as reações do exterior foram generalizadas, levando à revisão do pacote. Tanto mais que os Estados Unidos sempre primaram por fazer exigências de abertura de mercado aos outros países.

Em conjunturas como as que o mundo atravessa, é grande a cobrança sobre os governos para agir rápida e decisivamente, olhando apenas para dentro. Mesmo assim, é importante assinalar que a melhor alternativa de superação da crise é representada por medidas de coordenação, no lugar do salve-se quem puder. Diferentemente de 1929, existe atualmente um embrião de governança mundial composto por entidades multilaterais e fóruns de governantes (o G-20, sobretudo) capazes de promover a busca de soluções em conjunto. Na medida em que os diversos interesses e necessidades sejam pautados, teremos a chance de avançar numa direção construtiva. Isso significa, entre outras coisas, jogar o foco na produção e no trabalho, mais que no capitalismo financeiro e no rentismo sem freios; valorizar as políticas sociais, incluindo as estratégias de transferência de renda; e abordar com seriedade os desafios ambientais do planeta.

Uma crise envolve riscos, mas abre também oportunidades. A crise atual impôs um freio na "exuberância irracional" com que o capitalismo globalizado 
vinha trafegando. Um ritmo insustentável de consumo e de utilização de recursos que, sabemos, são limitados. A oportunidade de repensar esse caminho é fundamental e não pode ser perdida.

Notas

1 Cf. "Greenspan admite erro de ideologia à frente do FED" no site BBCBrasil.com, 23 de outubro de 2008. Ver também Greenspan (2007), onde o autor expõe mais longamente sua visão da dinâmica da economia e justifica as decisões que tomou.

2 Convém acrescentar que a aplicação dessa perspectiva de análise à América Latina foi enriquecida por meio das elaborações da Cepal e da exploração teórica da questão da dependência, em que se distinguiram Florestan Fernandes e Fernando Henrique Cardoso.

3 A bibliografia é relativamente extensa nesse campo que veio a adquirir o nome de Sociologia Histórica. Ver, como autores de referência, Bendix (1996) e Moore Junior (1975).

4 Sobre tais crises e como elas foram interpretadas, ver Krugman (2009).

Referências bibliográficas

BENDIX, R. Construção nacional e cidadania. São Paulo: Edusp, 1996.

DREIFUSS, R. A época das perplexidades - mundialização, globalização e planetarização: novos desafios. Petrópolis: Vozes, 1996.

ESPING-ANDERSEN, G. The three worlds of welfare capitalism. Princeton: Princeton University Press, 1990.

GALBRAITH, J. K. The great crash 1929. London: Penguin Books, 1977.

GERSCHENKRON, A. Economic backwardness in historical perspective. New York: Frederick A. Praeger, 1965.

GREENSPAN, A. The age of turbulence - adventures in a new world. New York: Penguin Books, 2007.

KRUGMAN, P. A crise de 2008 e a economia da depressão. Rio de Janeiro: Elsevier, 2009.

MOORE JUNIOR, B. As origens sociais da ditadura e da democracia; senhores e camponeses na construção do mundo moderno. Lisboa: Cosmos, 1975.

RICUPERO, R. A crise financeira e a queda do muro de Berlim. Estudos Avançados, São Paulo, v,22, n.64, 2008.

VACCA, G. Tra Itália e Europa: politiche e cultura dell'alternativa. Milano: FrancoAngeli, 1991.

RESUMO - O artigo trata da presente crise do capitalismo internacional, interessando-se pelo nexo entre seus aspectos propriamente econômicos e as questões políticas e insti- 
tucionais que ela suscita. São discutidos alguns elementos de caráter cognitivo e metodológico importantes para uma agenda de pesquisa da crise, e em seguida é apresentado um panorama do processo de globalização neoliberal que caracterizou o mundo nas ultimas décadas e que está no centro da crise contemporânea. O artigo conclui com uma breve prospecção das mudanças que poderão advir da crise, sobretudo no que diz respeito à revalorização da política e ao fortalecimento do papel do estado.

PALAVRAS-CHAVE: Crise econômica, Capitalismo, Globalização, Liberalismo, Estado, Economia internacional, Política internacional.

ABSTRACT - The article deals with the current crisis of world capitalism, relating its specifically economic aspects to political and institutional questions raised by the financial crash. It discusses some cognitive and methodological issues which are relevant for a research agenda of the process, followed by an overview of the development of neoliberal globalization. This model, which characterized the world during the last few decades, is in the heart of the contemporary economic problems. The article concludes with a brief prospect of the changes that may be stemming from the crisis, especially those related to the strengthening of politics and the state's role.

KEYWORDS: Economic crisis, Capitalism, Globalization, Liberalism, State, International economy, International politics.

Otavio Soares Dulci é sociólogo e cientista político, professor no mestrado em Relações Internacionais da PUC-Minas. @-osdulci@terra.com.br

Recebido em 2.3.2009 e aceito 6.3.2009. 